\title{
CLASSIFICATION FRAMEWORK OF LOCAL CLIMATE ZONES USING WORLD URBAN DATABASE AND ACCESS PORTAL TOOLS: CASE STUDY OF ALEXANDRIA CITY, EGYPT
}

\author{
SARAH M. ABOUGENDIA*, HANY M. AYAD \& ZEYAD T. EL-SAYAD \\ Department of Architectural Engineering, Alexandria University, Egypt.
}

\begin{abstract}
The effect of rapid urbanization on the urban climate has been studied in different cities worldwide. Facing the intricate impacts of changes in urban climate on inhabitants' wellbeing and environment, city planners are increasingly investigating climate determinants in their urban planning decisions. In Alexandria, Egypt, the urban morphology is characterized by high diversity that is expected to increase due to plans for future urban expansions. It is assumed that this diversity entails a variation in both physical and climatological characteristics of its urban canopy. In this context, climate-based classification of urban and rural areas, such as local climate zones could be used to support planning decisions. It assists in detecting the urban heat island and in documenting the urban surface properties, thus ensuring better decisions concerning the configuration of the built environment. This research adopts the method of the World Urban Database and Access Portal Tools, which employs a semi-automated classification of local climate zones. It combines pixel-based supervised classification of satellite imageries and local knowledge of the microscale built-up characteristics. While the method could be considered of average accuracy in terms of classification, training areas delineation and class interpretation, it gains specific importance due to its global implementation. This research presents a classification framework for the local climate zones based on incorporating several tools of extracting urban morphological characteristics. The study approach includes the following steps: (1) Identifying the morphological properties of the existing local climate zones types and subtypes using the available remotely sensed and geospatial data, (2) Classifying and digitizing the training areas of local climate zones classes from Google Earth satellite imageries, and (3) Automating the classification using the System for Automated Geoscientific Analysis. The introduced approach produces an enhanced local climate zones map that helps in identifying urban and natural features using their physical setting.

Keywords: local climate zones (LCZ), World Urban Database and Access Portal Tools (WUDAPT), geographic information systems (GIS).
\end{abstract}

\section{INTRODUCTION}

Many aspects play an essential role in assessing the impact of the urban environment on the climate of cities, such as land use, land cover, urban morphology, surface materials, human activities, and anthropogenic heat. Correspondingly, urban spatial data could be incorporated in urban climate analyses and computer models to give support in urban management and decision-making process. In this concern, transferring knowledge of urban climate into the decision-making process is considered as a remarkable trend in the recent studies of climate-oriented research [1], [2]. The field of urban climate has been adopted in intensive research in the last decades; more recent attention has focused on the classification schemes of the urban environment. Several classification schemes have been proposed to facilitate the exchange of interdisciplinary knowledge and to support metadata for climatic research [2]. The urban climate classification started by Chandler [3] who classified the greater region of London into four regions according to their climate, physiography and urban morphology. In

* ORCID: https://orcid.org/0000-0002-1953-3283 
the following years, several schemes were also implemented, the classification of St. Louis by Auer [4], Urban Terrain Zones (UTZ) by Ellefsen [5], Urban Climate Zones (UCZ) by Oke [6], U.S. National Land Cover Dataset (NLCD) by Homer et al. [7], and the National Land Cover Database (NLCD) of China by He et al. [8]. Stewart [9] identified the limitations of these schemes in some key points; first, the incorporation of climate-relevant characteristics in the classification criteria; among which, urban structure, land cover, urban fabric, and urban metabolism. Next, the imbalance occurs in terms of the ratio between the number of urban and rural classes, which must be proportionally attained. Regarding terminologies and purpose of the designated classes, these schemes vary in their interpretation of urban and rural classes and their adequacy in global implementation.

Therefore, to overcome limitations that could occur in the classification schemes, according to the issues mentioned above, the scheme of local climate zones (LCZs) classification was proposed by Stewart and Oke [10]. LCZs could provide a better understanding of the urban and natural environment through a structured typology of surface properties, explained next.

\section{LOCAL CLIMATE ZONES}

LCZs are defined as "regions of uniform surface cover, structure, material, and human activity that span hundreds of meters to several kilometres in horizontal scale" [10]. Seventeen zones could be depicted and distinguished by their physical characteristics and the screen height air temperature (measured at nearly $1.5 \mathrm{~m}$ above the ground). Table 1 depicts ten urban zones and seven natural zones that have a different combination of urban structure and landcover values.

Table 1: Physical characteristics of the local climate zones [10].

\begin{tabular}{|c|c|c|c|c|c|c|}
\hline Local climate zones & $\begin{array}{c}\text { Sky } \\
\text { view } \\
\text { factor }^{\mathrm{a}}\end{array}$ & $\begin{array}{l}\text { Aspect } \\
\text { Ratio }^{\text {b }}\end{array}$ & $\begin{array}{l}\text { Building } \\
\text { surface } \\
\text { fraction }^{\mathrm{c}} \\
(\%)\end{array}$ & $\begin{array}{l}\text { Impervious } \\
\text { surface } \\
\text { fraction }^{\mathrm{d}} \\
(\%)\end{array}$ & $\begin{array}{l}\text { Pervious } \\
\text { surface } \\
\text { fraction }^{\mathrm{e}} \\
(\%)\end{array}$ & $\begin{array}{l}\text { Height of } \\
\text { roughness } \\
\text { elements } \\
\text { f } \\
(\mathrm{m})\end{array}$ \\
\hline LCZ 1 Compact high-rise & $0.2-0.4$ & $>2$ & $40-60$ & $40-60$ & $<10$ & $>25$ \\
\hline LCZ 2 Compact midrise & $0.3-0.6$ & $0.75-2$ & $40-70$ & $30-50$ & $<20$ & $10-25$ \\
\hline LCZ 3 Compact low-rise & $0.2-0.6$ & $0.75-1.5$ & $40-70$ & $20-50$ & $<30$ & $3-10$ \\
\hline LCZ 4 Open high-rise & $0.5-0.7$ & $0.75-1.25$ & $20-40$ & $30-40$ & $30-40$ & $>25$ \\
\hline LCZ 5 Open midrise & $0.5-0.8$ & $0.3-0.75$ & $20-40$ & $30-50$ & $20-40$ & $10-25$ \\
\hline LCZ 6 Open low-rise & $0.6-0.9$ & $0.3-0.75$ & $20-40$ & $20-50$ & $30-60$ & $3-10$ \\
\hline $\begin{array}{l}\text { LCZ } 7 \text { Lightweight } \\
\text { low-rise }\end{array}$ & $0.2-0.5$ & $1-2$ & $60-90$ & $<20$ & $<30$ & $2-4$ \\
\hline LCZ 8 Large low-rise & $>0.7$ & $0.1-0.3$ & $30-50$ & $40-50$ & $<20$ & $3-10$ \\
\hline LCZ 9 Sparsely built & $>0.8$ & $0.1-0.25$ & $10-20$ & $<20$ & $60-80$ & $3-10$ \\
\hline LCZ 10 Heavy industry & $0.6-0.9$ & $0.2-0.5$ & $20-30$ & $20-40$ & $40-50$ & $5-15$ \\
\hline LCZA Dense Trees & $<0.4$ & $>1$ & $<10$ & $<10$ & $>90$ & $3-30$ \\
\hline LCZB Scattered Trees & $0.5-0.8$ & $0.25-0.75$ & $<10$ & $<10$ & $>90$ & $3-15$ \\
\hline LCZC Bush, Scrub & $0.7-0.9$ & $0.25-1.0$ & $<10$ & $<10$ & $>90$ & $<2$ \\
\hline LCZD Low plants & $>0.9$ & $<0.1$ & $<10$ & $<10$ & $>90$ & $<1$ \\
\hline LCZE Bare rock or paved & $>0.9$ & $<0.1$ & $<10$ & $>90$ & $<10$ & $<0.25$ \\
\hline LCZF Bare soil or sand & $>0.9$ & $<0.1$ & $<10$ & $<10$ & $>90$ & $<0.25$ \\
\hline LCZG Water & $>0.9$ & $<0.1$ & $<10$ & $<10$ & $>90$ & - \\
\hline
\end{tabular}

a: Ratio of the amount of sky hemisphere visible from ground level to that for an unobstructed hemisphere.

b: Mean height/ width of a street canyon (LCZs 1-7), building spacing (LCZs 8-10), and tree spacing (LCZs A-G).

c: Proportion of ground surface with building cover (\%).

$\mathrm{d}$ : Proportion of ground surface with impervious cover (rock, paved) (\%).

e: Proportion of ground surface with pervious cover (bare soil, plants, water) (\%).

f: Geometric average of building heights (LCZs 1-10) and tree/plant heights (LCZs A-F) (m). 
Additionally, LCZ types are described by their thermal characteristics, such as surface admittance, surface albedo and the anthropogenic heat output [11], [10]. Hence, the LCZs classification attempts to facilitate urban heat island measurements through the analysis of urban characteristics and impacts [9], and provides spatial data for urban climate models such as sky view factor, aspect ratio, and building surface fraction [12], [13].

Many researchers conducted the classification of local climate zones using two different methods. GIS-based and supervised pixel-based classification. Both methods have worldwide implementation adopted in identifying different types of LCZs, facilitating the data acquisition and mapping the urban and natural environment. Both methods differ in their procedure in data collection and classification explained by the following.

First, for the GIS-based method, the boundaries of LCZs are determined based on their physical parameters using geospatial dataset. According to Gál et al. [14], the method follows three steps: (i) calculating morphological parameters using a defined reference scale; (ii) using a rule-based classification to compare thresholds of defined LCZs by Stewart and Oke [10] with the calculated attributes in each polygon; (iii) clustering the classified polygons into the standardized zones of LCZs. Researchers who adopt the GIS-based method frequently use land surface properties such as area-weighted building height by Zheng et al. [2], Unger et al. [15], Wu et al. [16] and Hammerberg et al. [17]; or mean building height by Hidalgo et al. [18], Zhao et al. [19], and Quan [20]; besides, pervious and impervious surface fractions, aspect ratio, sky view factor and building surface fraction are used in most cases. Since the GIS-based method requires comprehensive planning data, it produces an accurate and detailed LCZs map. However, data inputs used in this method could differ in quality, components, and availability among cities.

Meanwhile, the supervised pixel-based classification method is designed to acquire land surface properties from satellite imageries and store spatial data using a proper pixel size [2]. It uses remotely sensed data and a proper machine learning algorithm, such as random forest, support vector machine, and neural networks [11], [21]. The method relies on preparing a set of samples for each LCZ class, known as training areas, which is used in the learning process. According to Gál et al. [14] and Bechtel et al. [11], the method follows four steps: (i) manual sampling of training areas using satellite imageries of Google earth, (ii) pre-processing of satellite imageries includes resampling imageries to an appropriate spatial resolution and clipping their boundaries with the area of interest, (iii) performing the classification with a proper classifier using the satellite imageries and training areas, and (iv) post-classification filtering of the produced map using the majority filter geoprocessing tool. The main benefits of using a pixel-based image classification are the possibility of using open-source data and software, the universality of the method and the ability of global implementation.

The two methods of GIS-based classification and the pixel-based image classification are incorporated in several implementations; the GIS-based approach identifies LCZs through the processing of morphological attributes. On the other hand, supervised pixel-based classification depends on the user's interpretation and delineation accuracy of LCZs training samples. Though the two methods utilize different sets of data inputs, enhanced LCZs production could benefit from both available morphology data and the user's local knowledge.

In this respect, the global initiative World Urban Database and Portal Tools (WUDAPT) adopts the supervised pixel-based approach in local climate zones classification [22]. WUDAPT has been proposed to rely on the LCZ concept in collecting the data of urban morphology and thermal characteristics. This method calls for participation from experts who have local knowledge of the urban structure of their cities. It has been proposed to fill the gap 
in data needed for climatic research, and to support coping with the challenges of sustainable cities and communities, the decision-making process and facilitating the climate actions [23]. However, the quality of WUDAPT LCZ maps is still recognized as a challenging problem, while WUDAPT is a bottom-up initiative; it depends on volunteering work in collecting urban data. Therefore, the quality of produced maps depends on collected data, user's interpretation of LCZs samples which might vary from case to case. Although several methods attempt to combine different tools and materials to assure the quality of LCZ maps, discrimination among LCZ types stays a current issue.

Consequently, this research aims at developing a framework for mapping local climate zones using a combined approach of the GIS-based techniques and the supervised pixel-based classification of WUDAPT method, for the city of Alexandria, Egypt. To achieve this aim, the study defines morphological parameters of LCZ classes in identifying the training areas; then, it analyses the spatial distribution of the local climate zones to depict the differences that occur in urban patterns of the city.

\section{LCZS METHODS AND TOOLS}

This section contributes to the following: (i) describing the urban patterns of the city context, and (ii) outlining the classification framework of local climate zones.

\subsection{Study area}

In Alexandria, Egypt, the urban morphology witnesses high diversity that is expected to increase due to plans for future urban expansions. It is assumed that this diversity entails a variation in both physical and climatological characteristics of its urban canopy. Alexandria city is selected as a prototype of high-density coastal urbanization. The city is located in the north coast of the Mediterranean Sea and expands on an area of almost $514.8 \mathrm{~km}^{2}$. Its population now exceeds 5.2 million people, with a growth rate of $2.10 \%$ from 1997 to 2017 [24]. The city is characterized by high density and low availability of expansion land. This condition caused the evolution of several urban patterns to accommodate population overspill.

As presented in Fig. 1, the city's urban patterns are defined in the Strategic Urban Plan Alexandria 2032 [25] into five different zones, first, the urban core area, which is characterized by the dense irregular pattern and the historic downtown. Many old buildings in the urban core were replaced with high-rise construction. Second, the peri-urban unplanned growth area, which accommodates unplanned illegally constructed residential areas on precious agricultural lands. Third, the western coastal urban expansion and inland expansion areas. Its northern part includes gated compounds, and resorts closed to industrial and logistics facilities. The southern side includes the lake Mariout and unplanned growth zone of suburban areas constructed along the lakefront. Finally, the rural areas with villages on farmlands are located south of the urban settlements.

The diversity of these patterns would be accompanied by heterogenous climatological characteristics of their urban canopy layer. Thus, this research attempts to provide an analysis of the spatial distribution of LCZs classes within these patterns.

\subsection{The workflow for local climate zones classification}

The research workflow adopts the classification process of the WUDAPT method, proposed by Bechtel et al. [11]. The workflow of LCZs classification of Alexandria includes three steps, illustrated in Fig. 2: First, identification of LCZs training areas, that comprises the 
following: (i) delineating the LCZs training areas using Google Earth with the aid of the knowledge accumulation of local climate zones and city structure, (ii) defining the morphological parameters and calculating each parameter for the selected training areas using ArcGIS software, (iii) revising/checking the calculated parameters of the identified training polygons in comparison with the LCZs parameters' thresholds. Second, automating LCZs WUDAPT classification using Landsat 8 satellite imageries and the final set of training polygons in SAGA GIS software. Third, investigating the spatial distribution of LCZs within the context of Alexandria, combined with urban patterns previously presented.
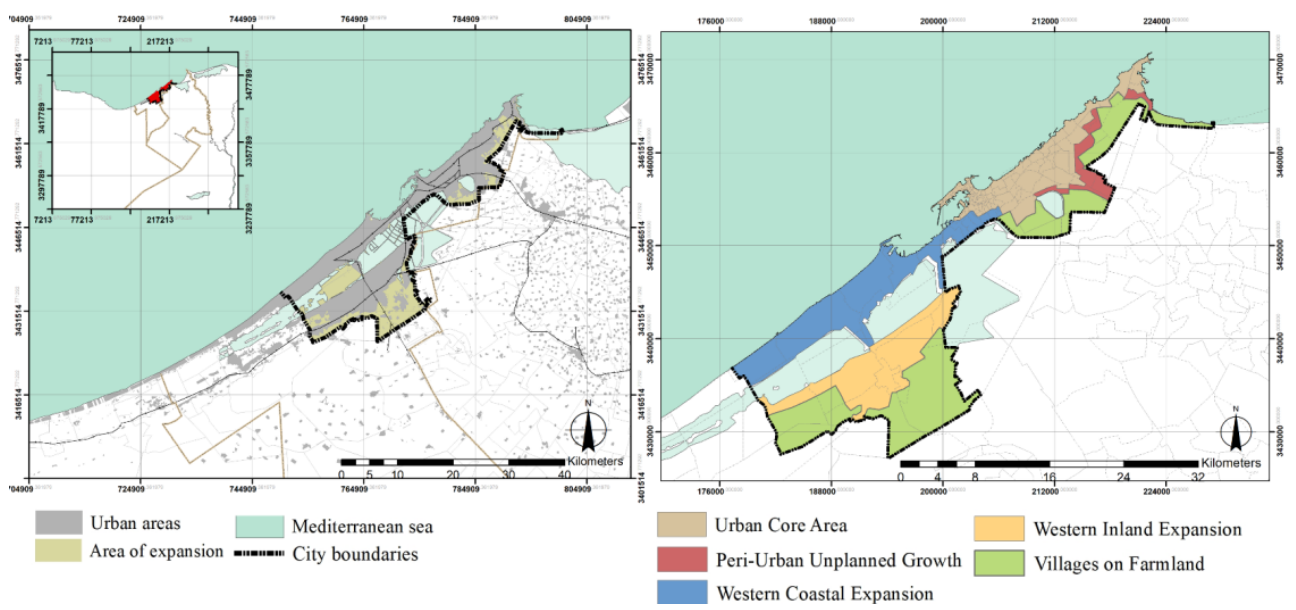

Figure 1: Left: Alexandria city illustrated with the boundary of expansion (delineated by GOPP); Right: patterns of the urban fabric of Alexandria; and Upper left: the location of Alexandria [24].

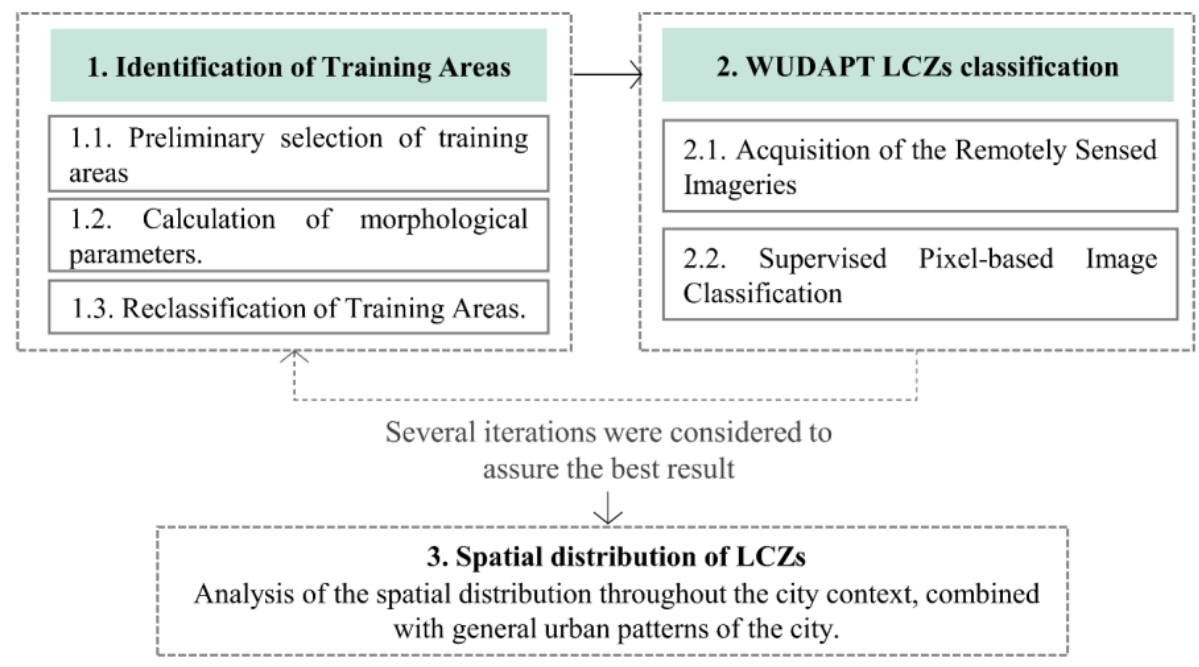

Figure 2: The applied workflow of local climate zones classification. 


\subsubsection{Identification of training areas}

The identification process of LCZs uses the morphological parameters to test the user's interpretation in digitizing the training areas. Consequently, it sets a framework to overcome the possible inconsistency in samples definition. To begin with, the training areas are digitized using Google earth satellite imageries. The region of interest is limited to the city's boundaries of expansion, determined by the General Organization of Physical Planning (GOPP). Hence, the distribution of selected samples depends on the defined region of interest. After that, the workflow of identifying the training areas comprises two filtration steps for the samples; first, the extraction of morphological parameters for the digitized areas. Next, the reclassification of the classes of training areas according to LCZs thresholds determined by Stewart and Oke [10].

\section{Extraction of the physical parameters}

After the selection and delineation of the training areas, these samples are exported to ArcGIS software for calculating the morphological parameters using the geospatial dataset. As for the extraction process, the physical properties have been defined in Table 2, and data acquisition is explained then, particularly, sky view factor is not included in this study.

Table 2: The main physical attributes of LCZs, explained by the definition and thresholds of data separation.

\begin{tabular}{|c|c|}
\hline Parameter & Definition \\
\hline \multirow{2}{*}{$\begin{array}{l}\text { Area-weighted } \\
\text { mean building } \\
\text { height }(\mathrm{mBH})\end{array}$} & $\begin{array}{l}\text { Mean height of roughness elements is defined as the average height of buildings or trees. } \\
\text { It is determined as a key parameter in identifying LCZ classes [2]. Stewart and Oke } \\
\text { categorized LCZs according to mean building height using thresholds, for high-rise, } \\
\text { midrise, and low-rise as } \mathrm{H}>25 \mathrm{~m}, \mathrm{H}=10-25 \mathrm{~m} \text {, and } \mathrm{H}=3-10 \mathrm{~m} \text {, respectively [10]. } \\
\text { However, as previously mentioned, many researchers calculate the average height to be } \\
\text { related to the built-up area [2], [15]-[17]. }\end{array}$ \\
\hline & $\begin{array}{l}\text { The area-weighted mean building height }(\mathrm{mBH}) \text { is given by the equation below: } \\
\qquad m B H=\frac{\sum n(B S A i * B H i)}{\sum B S A i}\end{array}$ \\
\hline $\begin{array}{l}\text { Building surface } \\
\text { fraction (BSF) }\end{array}$ & $\begin{array}{l}\text { Building surface fraction is defined as the total area of building footprint divided by the } \\
\text { area of the selected zone. The BSF is determined as a key parameter in identifying LCZ } \\
\text { classes [2]. It differentiates between the compact and open configuration of buildings in } \\
\text { LCZs. Stewart and Oke identify LCZs thresholds for compact, and open LCZs as BSF }> \\
40 \% \text {, and BSF }<40 \% \text {, respectively [10]. }\end{array}$ \\
\hline $\begin{array}{l}\text { Pervious surface } \\
\text { fraction (PSF) }\end{array}$ & $\begin{array}{l}\text { Pervious surfaces combine all land covers of vegetation, waterbody and bare soil [10]. PSF } \\
\text { is calculated as the total coverage area divided by the zone area from the selected samples. }\end{array}$ \\
\hline \multirow{2}{*}{$\begin{array}{l}\text { Impervious } \\
\text { surface fraction } \\
\quad(\text { ISF })\end{array}$} & $\begin{array}{l}\text { The impervious surface fraction is defined as the fraction of paved areas on the ground } \\
\text { area [10]. }\end{array}$ \\
\hline & $\begin{array}{l}\text { The impervious surface fraction (ISF) is generally calculated as below: } \\
\qquad I S F=1-(B S F+P S F), \\
\text { where BSF is the building surface fraction, and PSF is the pervious surface fraction. }\end{array}$ \\
\hline \multirow[b]{2}{*}{$\begin{array}{l}\text { Aspect ratio } \\
(\mathrm{H} / \mathrm{W})\end{array}$} & $\begin{array}{l}\text { Many researchers attempt to define the aspect ratio by the height }(\mathrm{H}) \text { to width }(\mathrm{W}) \text { of a } \\
\text { street canyon, which is widely examined as an important factor in climate-relevant studies. }\end{array}$ \\
\hline & $\begin{array}{l}\text { Consecutively, the aspect ratio of the street canyon }(\mathrm{H} / \mathrm{W}) \text { is calculated by two sides of the } \\
\text { street canyon by the following equation: } \\
\qquad H / W=(H r / W+H l / W) / 2 \text {, } \\
\text { where } \mathrm{Hr} / \mathrm{W} \text { is the aspect ratio of the right side of the street, and } \mathrm{Hl} / \mathrm{W} \text { is the aspect ratio } \\
\text { of the left side of the street. }\end{array}$ \\
\hline
\end{tabular}


Concerning data acquisition of the parameters mentioned above, for the $\mathrm{mBH}$, previous studies estimated its attributes from a high-resolution digital surface model (DSM); however, it is not available in most cases [17], [26], [27]. Otherwise, it could be extracted using vector geospatial datasets [2]. In this research, the values of $\mathrm{mBH}$ and BSF are extracted from the data for urban blocks scale provided by GOPP, and collected within the boundaries of each digitized training area using ArcGIS software. For the PSF and ISF, some approaches derive their values from satellite imageries using different methods [26], [28]. To simplify the process, the available data are used with no need for advanced techniques in data acquisition and analysis. The PSF is estimated based on a false colour composite image and the Google earth high-resolution imageries; then, pervious surfaces are delineated, and the ISF is calculated by eqn (2). Finally, the values of aspect ratio are computed using a tool provided by Cambridge Environmental Research Consultants (CERC) [29] to calculate the canyon height from geospatial data, then calculated by eqn (3).

\section{Reclassification of training samples}

The physical attributes are used to reclassify the preliminary delineated samples of LCZs. Concerning the discrimination among LCZ classes, researchers determine this process to begin with classifying areas into two groups of natural and urban areas [2], [19], [20]. In this research, only urban classes are examined according to their characteristics. This step is expected to test the accuracy of the training areas selection, besides, to assure the quality of training inputs in WUDAPT image classification.

As presented in Fig. 3, LCZs' thresholds of area-weighted mean building height are used to distinguish high-rise and midrise urban classes from low-rise urban classes, as next. If $\mathrm{mBH}$ is less than or equal to $10 \mathrm{~m}$, then the sample is defined as a low-rise category; if it is not, then the sample is considered to belong to the category of the high-rise to midrise classes. Consequently, the flowchart combines two paths described as follows:

First, the BSF is used for the discrimination among low-rise classes as follows: When BSF is more than $40 \%$, there are two possibilities; to identify the appropriate class from LCZ3 or LCZ8, interpreting the building footprint using the local knowledge of urban structure is needed. Meanwhile, when BSF is less than or equal to $40 \%$, two possibilities emerge as well; if BSF is more than $20 \%$, then the sample is identified as LCZ6; if it is not, it is LCZ9. Regarding the lightweight low-rise type (LCZ7), it is ignored in the adopted framework due to the rareness of this type in Alexandria.

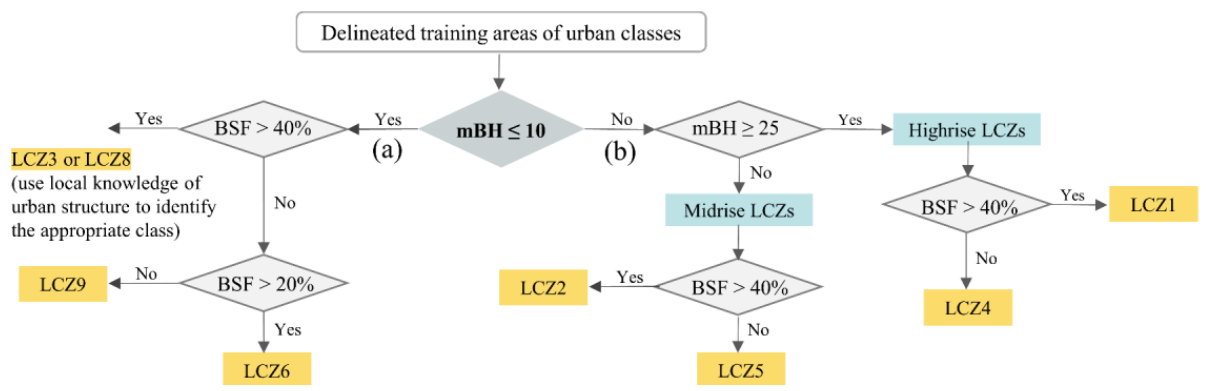

Figure 3: The flowchart of reclassification steps of LCZs classes for training areas. Two paths define the process. (a) The identification of low-rise urban classes; and (b) The identification of high-rise and midrise urban classes. 
Second, to discriminate between high-rise and midrise classes, the $\mathrm{mBH}$ is used for identifying the appropriate class. If $\mathrm{mBH}$ is more than or equal to $25 \mathrm{~m}$, then the sample is identified as high-rise LCZ. If it is not, the class is a midrise LCZ. Eventually, the two possibilities are divided into two categories; if BSF is more than or equal to $40 \%$, then the sample is defined as LCZ1, or LCZ2 for high-rise LCZs and midrise LCZs, respectively. If the previous query is not valid, then the sample is defined as LCZ4, or LCZ5 for high-rise LCZs and midrise LCZs, respectively.

Finally, regarding LCZ 10, land use maps and thermal bands of satellite imageries help to interpret the heavy industrial zones, with the aid of high-resolution imageries of Google Earth. After that, the final output of the identification process is prepared for the automated step of WUDAPT.

\subsubsection{WUDAPT classification of LCZs}

This step uses an embedded tool "Local Climate Zones classification" in SAGA GIS. It uses the random forest classifier in identifying the pixels' appropriate class, while the classification proceeded in the software [30]. Moreover, a spatial resolution of $100 \mathrm{~m} / \mathrm{pixel}$ is selected for raster classification, based on WUDAPT guidelines of scale definition. Data inputs that are imported in SAGA GIS include, first, the training areas that were previously digitized using Google earth with $\mathrm{kml}$ format, and reclassified using the extracted key parameters. Second, Landsat 8 satellite imageries are acquired from U.S. Geological Survey earth explorer site (USGS), with acquisition dates: 8 September 2015, 22 June 2016, 14 July 2018, 14 May 2019, and 5 October 2019; path and row are 178 and 38, respectively; and land cloud cover is less than $10 \%$. Landsat 8 OLI/TIR bands are selected to follow the proposed workflow of WUDAPT: Red (band 4), Green (band 3), Blue (band 2), NIR (band 5), SWIR (band 6 and 7) and TIR (band 10 and 11), projected to WGS 84/UTM zone 36N and resampled to $100 \mathrm{~m} /$ pixel. Then, the Random Forest algorithm of LCZs classification tool in SAGA GIS is used to produce the LCZ map. Therefore, the classified image is explored and compared with the high-resolution Google Earth imageries to observe misclassified areas of LCZ. Several iterations are considered to assure the best result of LCZs map using additional training data, which is added to overcome the misclassification. Table 3 presents the final set of the selected training areas. After the map is produced, post-classification processing is utilized using the majority filter tool in ArcGIS for deleting the isolated single pixels in LCZ large areas.

Table 3: The final set of selected training areas.

\begin{tabular}{|c|c|c|c|c|c|c|c|c|}
\hline \multirow{2}{*}{ Class } & \multirow{2}{*}{$\begin{array}{c}\text { Selected } \\
\text { training } \\
\text { areas }\end{array}$} & \multicolumn{5}{|c|}{ The extracted values of morphological properties } & \multirow{2}{*}{$\begin{array}{l}\text { Added } \\
\text { training } \\
\text { areas* }\end{array}$} & \multirow{2}{*}{$\begin{array}{c}\text { Total } \\
\text { number of } \\
\text { training } \\
\text { areas }\end{array}$} \\
\hline & & $\mathrm{H} / \mathrm{W}$ & $\begin{array}{l}\text { BSF } \\
(\%)\end{array}$ & $\begin{array}{c}\mathrm{mBH} \\
(\mathrm{m})\end{array}$ & $\begin{array}{l}\text { PSF } \\
(\%)\end{array}$ & $\begin{array}{l}\text { ISF } \\
(\%)\end{array}$ & & \\
\hline LCZ1 & 6 & $4-8$ & $52-80$ & $25-34$ & $0.0-7$ & $20-42$ & 2 & 8 \\
\hline LCZ2 & 11 & $1.2-5.3$ & $58-78$ & $11-24$ & $0.0-19.8$ & $18-42$ & 4 & 15 \\
\hline LCZ3 & 3 & $1-3.2$ & $53-66$ & $6-10$ & $0-3$ & $34-45$ & 3 & 6 \\
\hline $\mathrm{LCZ4}$ & 5 & $2-4.5$ & $25-40$ & $27-48$ & $10-64$ & $1-65$ & 0 & 5 \\
\hline LCZ5 & 5 & $0.5-3.25$ & $20-37$ & $11-20$ & $\begin{array}{c}17.4- \\
80.3\end{array}$ & $0.0-55.5$ & 2 & 7 \\
\hline LCZ6 & 6 & $0.0-1.5$ & $21-39$ & $8-10$ & $2-77$ & $1.8-59$ & 1 & 7 \\
\hline LCZ8 & 6 & $0.23-0.8$ & $50-81$ & $4-6$ & 0.0 & $18-50$ & 5 & 11 \\
\hline LCZ9 & 6 & $0-0.75$ & $6-25$ & $4-10$ & $63-93$ & $0-21.4$ & 7 & 14 \\
\hline
\end{tabular}

*A set of training areas is added to overcome the misclassification. 

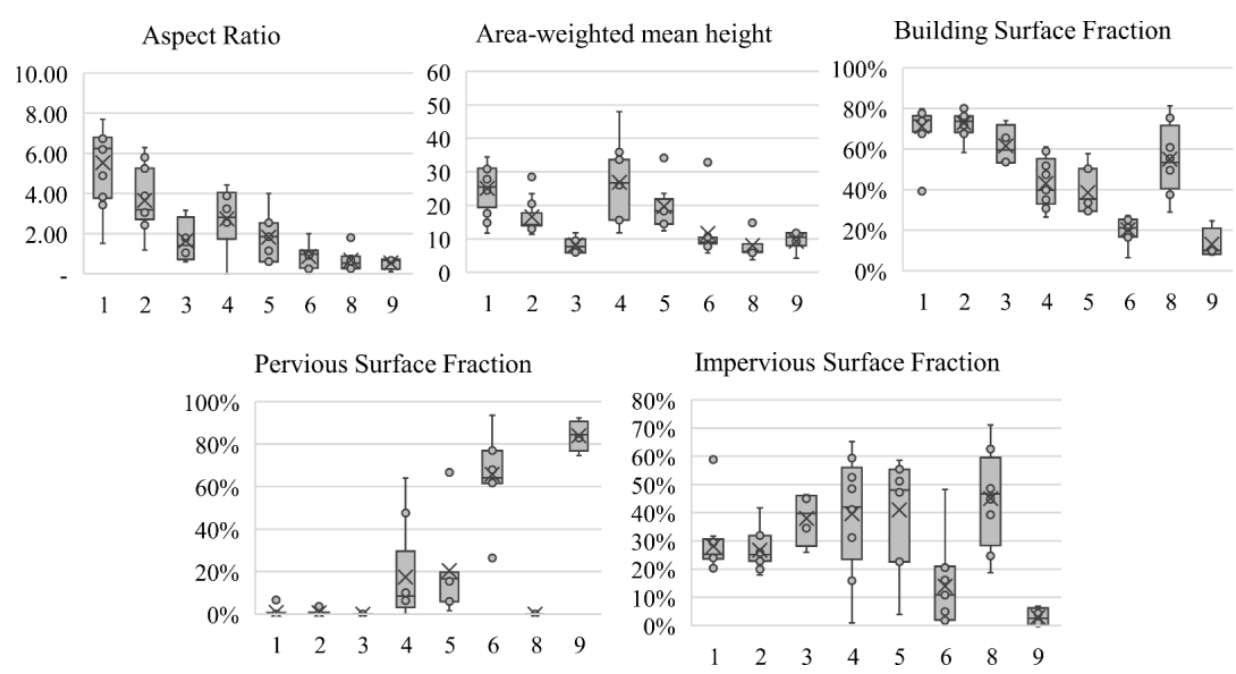

Figure 4: Boxplot charts of the extracted parameters, illustrating the ranges of values for the parameters before the reclassification process.

\section{RESULTS AND DISCUSSION}

The process of WUDAPT has taken into consideration the simplicity of the process and availability of data inputs; otherwise, the proposed framework is only considered to enhance the quality of training area selection. This section presents the results of the workflow that was previously presented.

\subsection{Identification of training areas}

Results of the identified training areas are presented from two aspects: the extracted physical parameters of training data and the proposed reclassification process. The data are analyzed using a boxplot chart to clarify the interrelationships among classes.

\subsubsection{Preliminary analysis of the extracted physical parameters}

Analysis of physical parameters is conducted to evaluate the selection of LCZ samples, depicted in Fig. 4. These parameters are evaluated according to the determined thresholds of LCZs as next.

First, regarding the aspect ratio, it is revealed that values are significantly above the determined thresholds. Particularly, thresholds of the aspect ratio of compact-urban classes are LCZ1: $>2$, LCZ2: $0.75-2$ and LCZ3: 0.75-1.5, while the collected data for these classes are 1.52-7.70, 0.60-6.29- and 0.60-3.17, respectively. Likewise, the thresholds of the aspect ratio of open-urban classes are LCZ 4: 0.75-1.25, LCZ5: 0.3-0.75 and LCZ6: $0.3-0.75$, while the extracted parameters are $1.54-4.42,0.60-4.0$ and $0.24-2.0$, respectively. It is observed that these values overlap among classes, and not clearly described LCZs classes, even though they are ascendingly graded from compacted to open classes. Consequently, the aspect ratio is not considered as a key parameter in the classification. Second, regarding the BSF, as can be expected, their values are ascendingly sorted from compact to open classes. However, these values reveal some conflicts in the definition of classes in terms of LCZs thresholds. Third, the values of $\mathrm{mBH}$ show intersections among 
high-rise, midrise and low-rise classes. Outliers occur in these values reveal inaccuracy in the selection of samples. Therefore, some extreme values are observed in $\mathrm{mBH}$ values of LCZ1 due to variations of building heights in the study area. Finally, the values of ISF show similar behaviour in all LCZs, while the PSF only occur in open urban classes and sparsely built zones, a result of the delineation of these surfaces that were ignored in the compact urban classes, large low-rise and heavy industry areas due to the high density and lack of vegetated and bare soil areas in the city context. According to these obtained values, the reclassification process was needed to enhance the selection of training samples by utilizing the discrimination among LCZs based on the $\mathrm{mBH}$ and BSF.

\subsubsection{Reclassification of training areas}

Based on the previously demonstrated results, building morphology, which is represented in $\mathrm{BSF}$ and $\mathrm{mBH}$, is used as a key criterion for reclassifying the digitized training samples in the LCZ classification. After that, observations are noticed as follows, depicted in Fig. 5.

First, analysis of physical properties reveals the removal of outliers, and the values range is adjusted to fit the definition of the classes. Second, it is observed that the surface cover parameters of pervious and impervious surface fractions, for classes LCZ1 to LCZ6, are negatively correlated with the factor of compaction. The LCZ9 class depicts the highest value of pervious surface faction and the lowest value of the impervious surface fraction. These zones combine a vast area of vegetation cover with unpaved roads covered with bare soil. Regarding classes of LCZ8 and LCZ10, the impervious surface fraction exposes higher values, while the pervious surface fraction reveals low values as the compacted classes.

In brief, based on the analysis above-demonstrated, several assumptions could be explained as follows: First, not all classes could be automatically reclassified using their physical properties. For instance, regarding LCZ3 and LCZ8, there is a need to accurately distinguish between the two LCZs using the visual interpretation of high-resolution satellite imageries; thus, pervious surfaces could be considered in this separation. Likewise, zones of LCZ10 need to be interpreted by additional information using land-use data and high-resolution satellite imageries. Second, in this study, the aspect ratio is not considered as a critical parameter in LCZs discrimination due to the overlaps occurred in their calculated values. It is argued that the thresholds of aspect ratio could vary among the different structure of cities.
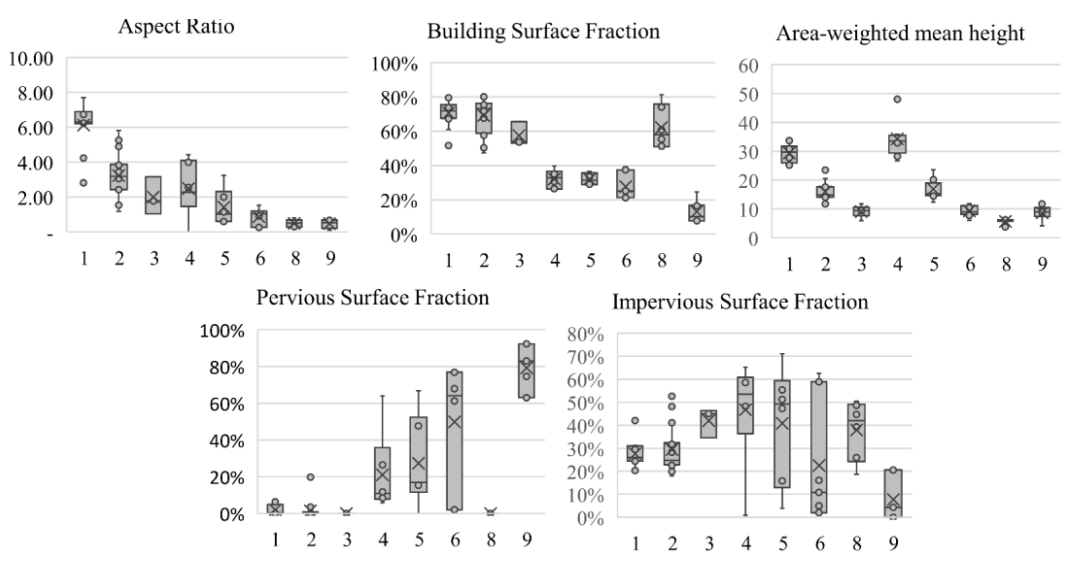

Figure 5: Boxplot charts of the extracted parameters, illustrating the ranges of values after the reclassification process. 


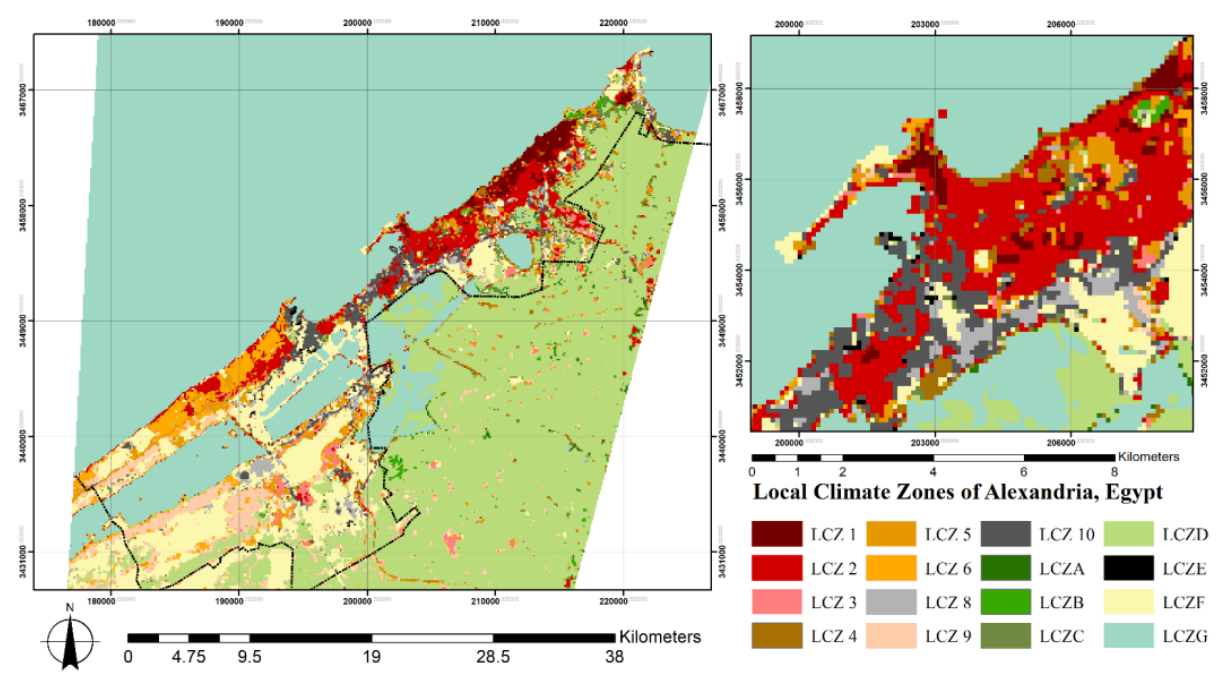

Figure 6: The local climate zones (LCZs) map of Alexandria. Left: the whole classified scene of LCZs map; and Right: the area of the old downtown shows the homogeneous urban morphology through LCZs classification.

\subsection{Spatial distribution of LCZs within the context of Alexandria}

Fig. 6 depicts the classified scene of local climate zones of Alexandria; it shows that the city structure includes 16 out of $17 \mathrm{LCZ}$ classes. The spatial distribution of these classes are described as follows: First, concerning natural classes, the majority of pixels are classified into LCZD (low plants), due to the vast area of agricultural lands distributed across the city. Therefore, there is a considerable occurrence of the desert lands on the western side of the city; their pixels are classified as LCZF (bare soil or sand). In contrast, other natural classes such as LCZA, LCZB, LCZC, and LCZE occurred with a low percentage. Second, concerning urban classes, compact and open zones appear in a modest percentage; otherwise, the total percentage of the ten urban classes equals to half of the rural classes and landcover.

In respect of zones of urban patterns, Fig. 7 shows a comparison of the percentage of LCZs' occurrence. According to the previously described patterns of the study area, the spatial distribution of LCZs is explained as follows: First, most areas occupied by the urban core are classified into compact urban areas with high-rise and midrise categories. Particularly, over $50 \%$ of compact areas are distributed by roughly $18 \%, 32 \%$, and $2 \%$ for LCZ1 and LCZ2, and LCZ3, respectively. Besides, about $14 \%$ of the area is classified into open classes, distributed by nearly $5 \%, 8 \%$, and $1 \%$ for LCZ4, LCZ5, and LCZ6, respectively. Then about $13 \%$ of the urban core is classified into various classes of LCZ8, LCZ9, and LCZ10. Zones of land cover occupied with scattered trees, bare soil and sands are classified with occurrence by nearly $21 \%$. Second, the unplanned growth zone combines a close percentage of LCZs with the urban core, but a higher percentage of LCZ3, about 10\%, and a lower percentage of LCZ1, nearly $10 \%$. Third, regarding the western expansion zone, most of the areas are described as open classes of urban areas represent the zones of vacation houses and resorts, it has a vast area of industrial zones combined the heavy industrial area, and storages as well. It is noticed that the percentage of urban classes exceeds $60 \%$ of the total area for the coastal side and approximately $50 \%$ for the southern side. The latter includes 
the industrial zones and large low-rise areas that occur around $15 \%$ for both zones. Besides, the percentage of the rural classes includes sparsely built and landcover surfaces which are classified by almost $36 \%$, and $61 \%$ in the coastal and southern zones, respectively. Fourth, rural areas show a significant percentage of LCZD and LCZF by nearly $40 \%$ and $32 \%$, respectively. Urban areas are shown in a small percentage, around $14 \%$ of scattered agglomerations and villages. The LCZ9 are represented as scattered buildings along the main roads and areas that occupy agricultural lands, roughly $9 \%$.

To sum up, the classified map of the LCZs of Alexandria sums up to that the city witnesses a significant variety of urban structure, starting from the urban core, passing by the coastal development in the west side to the southern urban growth areas. The previously demonstrated results confirm that the defined training data with their physical parameters is a considerable way to enhance the quality of the LCZs classification. Furthermore, not all physical properties have the same significance in LCZs definition, some extreme values are identified; in the case of Alexandria city, namely: (1) the aspect ratio is recognized to deviate from classes thresholds depending on the city structure; (2) it is noticed that the compaction of most areas is higher than the classes thresholds that determined in other cities by Stewart and Oke. Moreover, regarding the spatial distribution of LCZs in Alexandria, the city's urban patterns are investigated following the spatial distribution of local climate zones. It is recognized that the LCZs map could be used to observe the homogeneity and heterogeneity of the city structure.

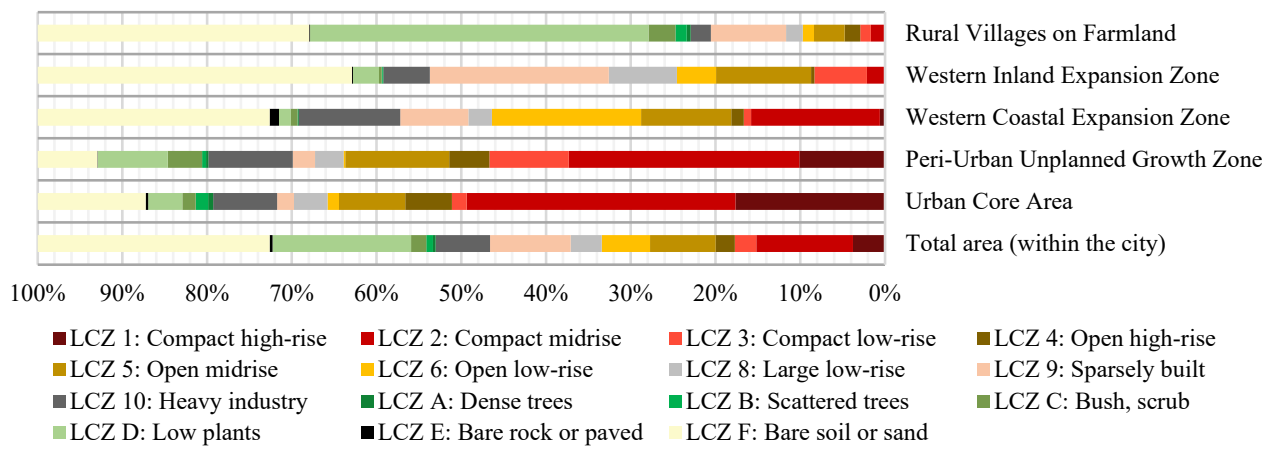

Figure 7: The occurrence of LCZs within Alexandria's urban patterns and the entire context.

\section{CONCLUSION}

It is recognized that the characteristics of urban morphology could be standardized using classification schemes, among which, the adopted scheme of local climate zones (LCZs). Hence, this research aimed at utilizing a framework for classifying the LCZs of Alexandria city using WUDAPT method. It has considered the gap that has been identified in previous researches as the average accuracy in terms of definition, delineation and user's interpretation of LCZs training areas. The findings of this research confirm that the parameterization of training zones using urban morphological properties could enhance the quality of LCZs map produced using pixel-based image classification. However, the transferability of spatial data for LCZs identification would be a critical issue due to the variance occurred in the extracted values of morphological parameters, compared with Stewart and Oke thresholds. Besides, the proposed framework would facilitate the usage of different methods and materials for spatial data collection. Nevertheless, the usage of physical properties depends on the 
availability and the quality of planning data used in the extraction method. These tools and data inputs could be replaced with the appropriate ones, whether using field visit, high-resolution satellite imageries or geospatial datasets, as mentioned before, there is not an optimum methodology in LCZs classification.

\section{REFERENCES}

[1] Ng, E. \& Ren, C., The Urban Climatic Map: A Methodology for Sustainable Urban Planning, Routledge: London, 528 pp., 2015.

[2] Zheng, Y. et al., GIS-based mapping of local climate zone in the high-density city of Hong Kong. Urban Climate, 24, pp. 419-448, 2018.

DOI: 10.1016/j.uclim.2017.05.008.

[3] Chandler, T.J., London's urban climate. The Geographical Journal, 128(3), pp. 279298, 1962. DOI: $10.2307 / 1794042$.

[4] Auer, A.H., Correlation of land use and cover with meteorological anomalies. Journal of Applied Meteorology, 17, pp. 636-643, 1978.

DOI: $10.1175 / 1520-0450(1978) 017<0636$ :COLUAC $>2.0 . C O ; 2$.

[5] Ellefsen, R., Mapping and measuring buildings in the canopy boundary layer in ten U.S. cities. Energy and Buildings, 16, pp. 1025-1049, 1991.

DOI: 10.1016/0378-7788(91)90097-M.

[6] Oke, T.R., Initial guidance to obtain representative meteorological observations at urban sites. World Meteorological Organization, Report No. 81, 2004.

[7] Homer, C.G. et al., Completion of the 2001 National Land Cover Database for the conterminous United States. Photogrammetric Engineering and Remote Sensing, 73, pp. 337-341, 2007.

[8] He, J.F., Liu, J.Y., Zhuang, D.F., Zhang, W. \& Liu, M.L., Assessing the effect of land use/land cover change on the change of urban heat island intensity. Theoretical and Applied Climatology, 90, pp. 217-226, 2007. DOI: 10.1007/s00704-006-0273-1.

[9] Stewart, I.D., Redefining the urban heat island. $\mathrm{PhD}$ thesis, The University of British Columbia, 2011.

[10] Stewart, I.D. \& Oke, T.R., Local climate zones for urban temperature studies. Bulletin of the American Meteorological Society, 93, pp. 1879-1900, 2012.

DOI: 10.1175/BAMS-D-11-00019.1.

[11] Bechtel, B. et al., Mapping local climate zones for a worldwide database of the form and function of cities. ISPRS International Journal of Geo-Information, 4, pp. 199219, 2015. DOI: 10.3390/ijgi4010199.

[12] Oke, T.R., The energetic basis of the urban heat island. Quarterly Journal of the Royal Meteorological Society, 108, pp. 1-24, 1982. DOI: 10.1002/qj.49710845502.

[13] Danylo, O., See, L., Bechtel, B., Schepaschenko, D. \& Fritz, S., Contributing to WUDAPT: A local climate zone classification of two cities in Ukraine. IEEE Journal of Selected Topics in Applied Earth Observations and Remote Sensing, 9, pp. 18411853, 2016. DOI: 10.1109/JSTARS.2016.2539977.

[14] Gál, T., Bechtel, B. \& Unger, J., Comparison of two different local climate zone mapping methods. ICUC9-9th International Conference on Urban Climates, Toulouse, France, 20-24 Jul., pp. 1-6, 2015.

[15] Unger, J., Lelovics, E. \& Gál, T., Local climate zone mapping using GIS methods in Szeged. Hungarian Geographical Bulletin, 63, pp. 29-41, 2014.

DOI: 10.15201/hungeobull.63.1.3. 
[16] Wu, Y., Sharifi, A., Yang, P., Borjigin, H., Murakami, D. \& Yamagata, Y., Mapping building carbon emissions within local climate zones in Shanghai. Energy Procedia, 152, pp. 815-822, 2018. DOI: 10.1016/j.egypro.2018.09.195.

[17] Hammerberg, K., Brousse, O., Martilli, A. \& Mahdavi, A., Implications of employing detailed urban canopy parameters for mesoscale climate modelling: A comparison between WUDAPT and GIS databases over Vienna, Austria. International Journal of Climatology, 38, pp. e1241-e1257, 2018. DOI: 10.1002/joc.5447.

[18] Hidalgo, J. et al., Comparison between local climate zones maps derived from administrative datasets and satellite observations. Urban Climate, 27, pp. 64-89, 2019. DOI: 10.1016/j.uclim.2018.10.004.

[19] Zhao, C., Jensen, J., Weng, Q., Currit, N. \& Weaver, R., Application of airborne remote sensing data on mapping local climate zones: Cases of three metropolitan areas of Texas, U.S. Computers, Environment and Urban Systems, 74, pp. 175-193, 2019. DOI: 10.1016/j.compenvurbsys.2018.11.002.

[20] Quan, J., Enhanced geographic information system-based mapping of local climate zones in Beijing, China. Science China Technological Sciences, 62, pp. 2243-2260, 2019. DOI: 10.1007/s11431-018-9417-6.

[21] Xu, Y., Ren, C., Cai, M., Edward, N.Y.Y. \& Wu, T., Classification of local climate zones using ASTER and Landsat data for high-density cities. IEEE Journal of Selected Topics in Applied Earth Observations and Remote Sensing, 10, pp. 3397-3405, 2017. DOI: 10.1109/JSTARS.2017.2683484.

[22] Bechtel, B. et al., Generating WUDAPT level 0 data - current status of production and evaluation. Urban Climate, 27, pp. 24-45, 2019. DOI: 10.1016/j.uclim.2018.10.001.

[23] Bechtel, B. et al., Census of cities: LCZ classification of cities (level 0) - workflow and initial results from various cities. ICUC9 - 9th International Conference on Urban Climate, 2015.

[24] CAPMAS, Egypt in figures, 4-15, 2019.

[25] AS\&P, Strategic urban plan Alexandria 2032, detailed city profile, 2014.

[26] Mitraka, Z., Del Frate, F., Chrysoulakis, N. \& Gastellu-Etchegorry, J-P., Exploiting earth observation data products for mapping local climate zones. 2015 Joint Urban Remote Sensing Event (JURSE): Lausanne, pp. 1-4, 2015.

DOI: 10.1109/JURSE.2015.7120456.

[27] Wicki, A. \& Parlow, E., Attribution of local climate zones using a multitemporal land use/land cover classification scheme. Journal of Applied Remote Sensing, 11, 026001, 2017. DOI: $10.1117 / 1 . J R S .11 .026001$.

[28] Weng, Q., Remote sensing of impervious surfaces in the urban areas: Requirements, methods, and trends. Remote Sensing of Environment, 117, pp. 34-49, 2012. DOI: $10.1016 /$ j.rse.2011.02.030.

[29] Cambridge Environmental Research Consultants (CERC). www.cerc.co.uk/index.php.

[30] Conrad, O. et al., System for Automated Geoscientific Analyses (SAGA) v. 2.1.4, Geoscientific Model Development, 8, pp. 1991-2007, 2015.

DOI: $10.5194 /$ gmd-8-1991-2015. 